\title{
Analysis of Military Training Security Risk Assessment Method Based on F-ANP
}

\author{
Authors Name: Pan Yunlin ${ }^{1, \mathrm{a}}$, Authors Name: Yi Wenan ${ }^{2, \mathrm{~b} *}$, Authors Name: Gao Yong ${ }^{3, \mathrm{c}}$, Authors Name: Wang Yongbin ${ }^{4, \mathrm{~d}}$ \\ ${ }^{1}$ Dept. name of organization: National University of Defense Technology, Changsha, Hunan, China \\ ${ }^{2}$ Dept. name of organization: National University of Defense Technology, Changsha, Hunan, China \\ ${ }^{3}$ Dept. name of organization: National University of Defense Technology, Changsha, Hunan, China \\ ${ }^{4}$ Dept. name of organization: National University of Defense Technology, Changsha, Hunan, China
}

\begin{abstract}
Combining the arm training practice after the Strong Army Reform, this paper put forwards using the F-ANP method for military training security risks to semi- quantitative evaluation, builds the safety risk assessment index system of military training, semi-quantitative calculation and analysis, and put forwards the opinions of the security risk prevention and control suggestions. This paper enriches the military training of security risk assessment methods, and provides the reference to the research of military training safety risk assessment.
\end{abstract}

\section{Introduction}

The newly revised $<$ Regulations on Military Safety Management> clearly states that " Safety management is the comprehensive and regular basic work of military construction, and the basic guarantee for the successful completion of various tasks such as military training and war preparation" , " The establishment of safety risk analysis and prevention and control system is the basic task of safety management. Safety risk assessment should be carried out in advance when organizing major activities and carrying out dangerous tasks "[1]. After the Army Reform, the actual combat characteristics of army training are more and more prominent, the training standards are higher and higher, and the security risks are higher and higher. Paying attention to the safety management of training and preventing the occurrence of safety accidents are the important basis for completing the training task with high standards and ensuring the generation and improvement of combat effectiveness. However, safety risk exists objectively. Human initiative can only control and reduce the risk, can't completely eliminate the risk. In the practice of training, we found that most troops put safety management in a more important position in the process of development and construction. The occurrence of accidents often means "one-vote veto", which has a serious impact on the troop construction, which leads to the contradiction between safety management and training quality. In order to improve the quality of training, some troops simply regardless of the objective reality, ignore the safety risk, which result in training accidents. While, in order to ensure the safety of training, the prevention of training safety at some troops is comprehensive, the safety prevention and control is not targeted which involving a lot of energy, which is not conducive to the improvement of the quality of military training; what's more, in order to ensure safety, some troops regardless of the quality of training, randomly reduce the training standards which hinder the generation and improvement of combat effectiveness. At a deeper level, these problems will seriously hinder the generation and improvement of combat effectiveness, which is not in line with the original intention of the Army Reform. Therefore, effective safety risk assessment and proper safety management in training that not only effectively reduce the safety risk, but also complete the training task with high standard, has become an urgent problem to be solved in the current training safety management.

\section{Military Training Security Risk Assessment Index System}

According to the $<$ Regulations on Military Safety Management $>$, the safety risk assessment mainly carries out qualitative and quantitative analysis and evaluation on the unsafe behaviors of people, the unsafe state of objects and the unsafe factors of environment, determines the risk level, and puts forward suggestions and countermeasures to avoid or reduce the risk. ${ }^{[1]}$ Therefore, the security risk factors in military training should be determined mainly from the above three aspects.

\subsection{Construction Principles}

The security of military training is affected by many factors. The following principles should be followed when constructing the evaluation system.

- First, the principle of target demand. Military training is a complex system, involving training,

ae-mail: 791094817@qq.com, b* Corresponding author: byiwenan123@163.com

ce-mail: gaoyong1020@163.com, de-mail: 694302076@qq.com 
life, security and other aspects. During this period, a variety of safety accidents may occur, including social accidents, training accidents, management accidents, etc. The reasons may arise from training preparation, training implementation, accident disposal and other stages. This paper mainly analyzes the safety risks in the process of training implementation.

- Second, the principle of objective truth. The security of military training is affected by many factors, and many of them are uncertain, that is, they can not be measured by an accurate value. Therefore, in the evaluation of each index, the influence of human subjective factors should be fully considered to minimize the influence. Therefore, in the evaluation of risk factors, the subjective mentality of the rater should be taken into account to improve the objectivity of the evaluation.

- Third, the principle of comprehensiveness and accuracy. Various factors involved in military training security will interact with each other. The change of one factor may cause significant changes in the risk of other factors. For example, the change of training environment temperature may cause changes in human tolerance risk. Therefore, on the one hand, the identification of risk factors should be comprehensive, without missing items; on the other hand, the construction of the relationship between risk factors should be reasonable, not comprehensive, and the interaction between the main factors should be considered to eliminate the negligible relationship.

\subsection{Analysis of Safety Risk Factors}

With the development of economic society, "safety risk" has been given more and more meanings. It has a wide influence in politics, economy, military, transportation, society, culture and art, and is more and more closely related to the decision-making of management and the behavior of ordinary people. Effective analysis of safety risk factors is the premise and basis of safety management decision-making. Security risk in military training refers to all kinds of risk factors existing in the process of military training, which have adverse effects on personnel, equipment or training, and may cause casualties, equipment loss or reduce the quality and efficiency of training. This paper only analyzes the casualties in training.

According to the cause chain analysis of military training safety accidents ${ }^{[3]}$, the risk factors leading to training safety accidents are divided into direct factors and indirect factors. Direct factors refer to the factors that may directly lead to accidents once such factors exist, and indirect factors refer to the factors that affect the direct factors, which may lead to the occurrence of direct factors and then lead to safety accidents. For example, the direct causes of heatstroke in training are high temperature, high training intensity and poor physical condition. The reasons for poor physical condition may be poor training tolerance and illness. The reasons for high training intensity may be poor training basis and unreasonable training plan. Here, high temperature, high-intensity training and poor physical condition are the direct factors, while poor tolerance, illness, poor training foundation and unreasonable planning are the indirect factors. Combined with the investigation, the direct factors leading to training safety accidents are mainly one or more factors, such as the unsafe factors of environment, unsafe behaviors of people and unsafe state of objects. The unsafe factors of environment mainly refer to weather, terrain, disease epidemic situation, etc.; the unsafe behavior of human mainly refers to the equipment operation or training action of individual personnel is not standardized, and the training organization activity is not standardized, etc.; the unsafe state of objects mainly refers to the state of human itself, the state of weapon equipment, the nature requirements of training, etc.

Indirect factors affect direct factors, but direct factors do not affect indirect factors. Therefore, in the analysis of training safety risk factors, we should distinguish between direct factors and indirect factors. Combined with the training practice of a unit, the direct risk factors leading to safety accidents in training are shown in Figure 1.

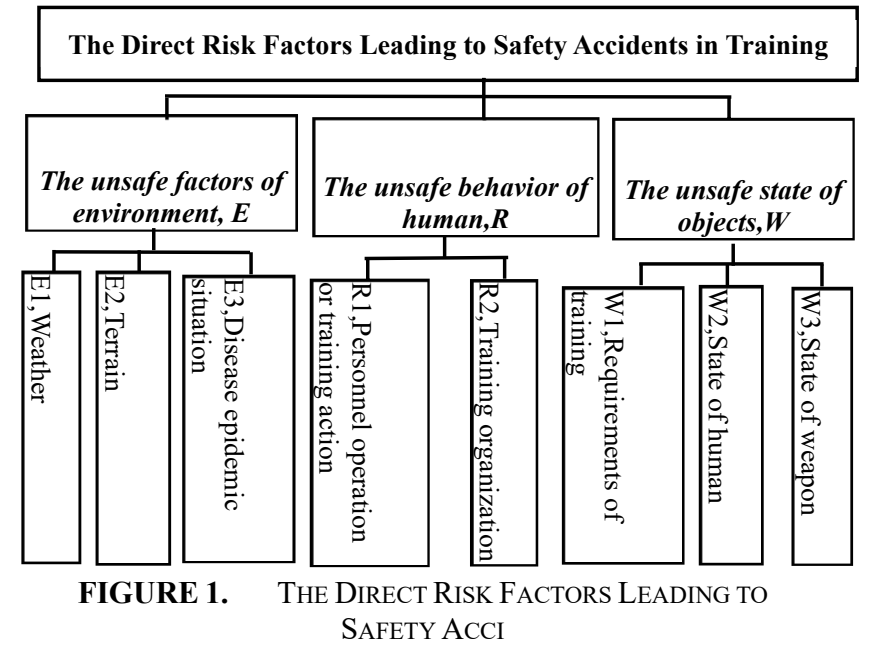




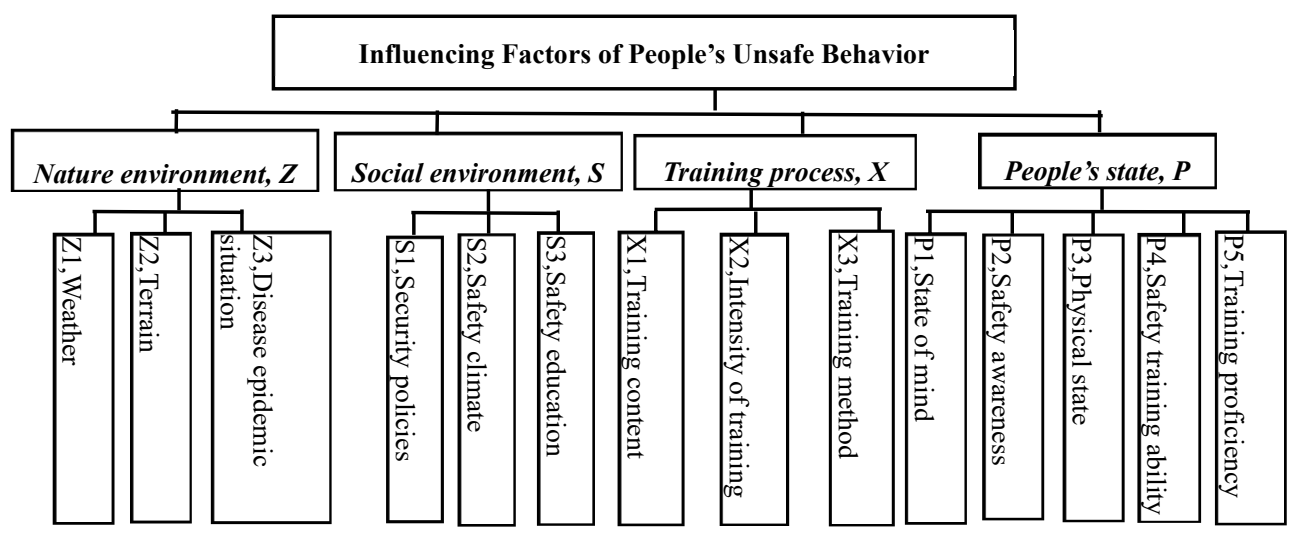

FIGURE 2. InFLUENCING FACTORS OF PEOPLE'S UNSAFE BEHAVIOR

Among the direct safety risk factors causing safety accidents, the unsafe factors of the environment are obvious, and the relevant measures can be taken directly to reduce the risk of environmental factors, and have little impact on the quality of training. According to the analysis of people's unsafe behavior, the risk is affected by different factors, including subjective factors and objective factors. It is difficult to reduce the risk directly through a certain prevention and control measures, so comprehensive prevention and control must be carried out in many aspects. Specifically speaking, personal actions, operations and training management organizations are affected by people's own state, training process, natural environment and social environment. People's own state is mainly ideological state, safety awareness, physical state, training proficiency and training ability; training process is mainly training content and training intensity; natural environment is mainly weather, terrain and epidemic situation. Social environment mainly refers to safety system, safety atmosphere and safety education. By analyzing the unsafe state of objects, we can see that it is mainly affected by human behavior. Therefore, the indirect factors leading to training safety accidents should be analyzed according to human behavior, and the correlation is shown in Figure 2.

\section{Quantitative Evaluation Model of Military Training Security Risk}

In the process of military training, there are many security risk factors, which are difficult to quantify directly, and each factor is not independent of each other. There are mutual influences between them. For example, in low or high temperature, human training tolerance will be significantly affected, resulting in increased risk. That forms a complex system with unclear structure and multilevel. Analytic network process (ANP) is a method of weight calculation for complex multilevel network model. It is put forward by Professor T. L. Saaty, an American operational research scientist, on the basis of analytic hierarchy process (AHP). It takes into account the mutual influence of various factors in the system, and extends the special situation that each factor of AHP is independent to the general situation. It can systematize and hierarchize complex problems, which is more in line with the reality.

\subsection{Theoretical Basis of ANP}

ANP structure model is composed of control layer and network layer. The control layer is divided into decision objectives and decision criteria. Decision objectives are the results of system analysis. Decision criteria are dominated by decision objectives, and each criterion is independent of each other. Network layer is composed of all elements dominated by control layer, and each element is allowed to influence each other to form a network structure. The general ANP structure is shown in Figure $3^{[5]}$. 


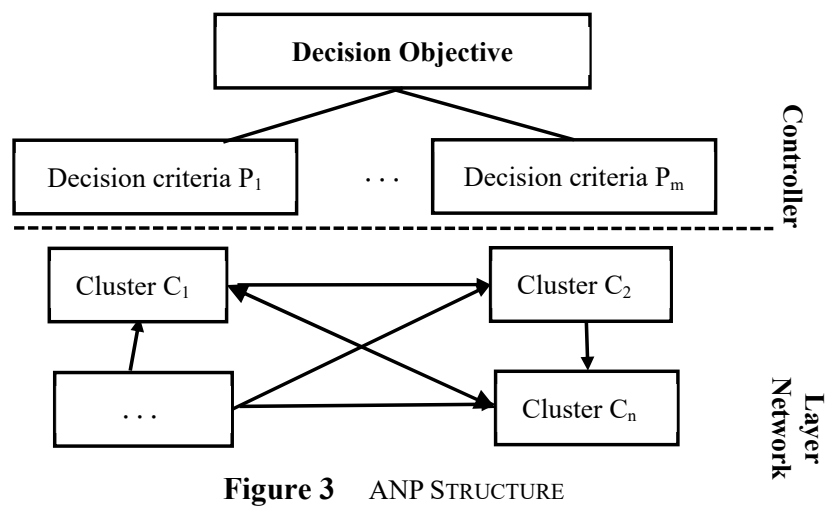

Suppose that there are $\mathrm{m}$ decision criteria $\mathrm{P}_{1}, \mathrm{P}_{2}, \ldots, \mathrm{P}_{\mathrm{m}}$ in the ANP structure model, and there are $\mathrm{n}$ element groups $\mathrm{C}_{1}, \mathrm{C}_{2}, \cdots, \mathrm{C}_{\mathrm{n}}$ in the network layer, among which, there are elements $e_{i l}, e_{i 2}, \cdots, e_{i r}$. First, we need to build the relationship between the elements in the network layer, $e_{i j} \rightarrow e_{k r}$ means that the elements $e_{i j}$ in the cluster $\mathrm{C}_{i}$ are affected by the elements $e_{k r}$ in the cluster $\mathrm{C}_{k}$. Under a certain decision criterion $\mathrm{Ps}_{\mathrm{s}}$, the influence of the elements $e_{k r}$ in the cluster $C_{k}$ is compared for the sub criterion $e^{e_{i j}}$, the comparison matrix $W_{i j}$ under the criteria $P_{s}$ is constructed, and then the weight vectors are calculated respectively. By analogy, we can get the super matrix of the influence of each element on the cluster $C_{i}$ under the decision criteria $P_{s}$.

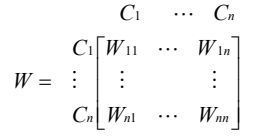

Under the decision criterion $P_{s}$, the weight matrix is obtained by comparing the importance of cluster $C_{i}$.

$$
A=\left[\begin{array}{ccc}
a_{11} & \cdots & a_{1 \mathrm{n}} \\
\vdots & & \vdots \\
a_{\mathrm{n} 1} & \cdots & a_{\mathrm{nn}}
\end{array}\right]
$$

When constructing the data of each matrix, we should pay attention to the consistency test to ensure the reliability of the data. Using Super Decisions software to calculate, we can get the relative weight of each element in the network layer, and make corresponding decisions according to the weight value of different elements.

\subsection{ANP Model Construction of Military Training Security Risk}

Combined with the actual investigation and expert evaluation, the internal relationship between various factors is determined, as shown in Table I and table II (" indicates that column elements affect row elements).

Table I. The Relationship Between Direct Factors of Training Total Accident

\begin{tabular}{|l|c|c|c|c|c|c|c|}
\hline & $\boldsymbol{E 1}$ & $\boldsymbol{E 2}$ & $\boldsymbol{E 3}$ & $\boldsymbol{R 1}$ & $\boldsymbol{R 2}$ & $\boldsymbol{W 1}$ & $\boldsymbol{W} 2$ \\
\hline $\boldsymbol{E} 1$ & & $\sqrt{ }$ & $\sqrt{ }$ & $\sqrt{ }$ & $\sqrt{ }$ & $\sqrt{ }$ & $\sqrt{ }$ \\
\hline $\boldsymbol{E} 2$ & & & & $\sqrt{ }$ & $\sqrt{ }$ & $\sqrt{ }$ & $\sqrt{ }$ \\
\hline $\boldsymbol{E 3}$ & & & & $\sqrt{ }$ & $\sqrt{ }$ & $\sqrt{ }$ & \\
\hline $\boldsymbol{R} 1$ & & & & & $\sqrt{ }$ & $\sqrt{ }$ & $\sqrt{ }$ \\
\hline $\boldsymbol{R} 2$ & & & & $\sqrt{ }$ & & $\sqrt{ }$ & $\sqrt{ }$ \\
\hline
\end{tabular}

\begin{tabular}{|l|l|l|l|l|l|l|l|}
\hline $\boldsymbol{R} 3$ & & & & $\sqrt{ }$ & $\sqrt{ }$ & $\sqrt{ }$ & \\
\hline $\boldsymbol{W} \boldsymbol{1}$ & & & & $\sqrt{ }$ & $\sqrt{ }$ & & \\
\hline $\boldsymbol{W} 2$ & & & & & $\sqrt{ }$ & $\sqrt{ }$ & \\
\hline
\end{tabular}

Table II. The Relationship Between the Influencing Factors of People's Unsafe Unsafe Behavior

\begin{tabular}{|l|l|c|c|c|c|c|c|c|c|c|c|c|c|c|}
\hline & $Z 1$ & $Z 2$ & $Z 3$ & $S 1$ & $S 2$ & $S 3$ & $X 1$ & $X 2$ & $X 3$ & $P 1$ & $P 2$ & $P 3$ & $P 4$ & $P 5$ \\
\hline$Z 1$ & & $\sqrt{ }$ & $\sqrt{ }$ & & & & & & $\sqrt{ }$ & & & $\sqrt{ }$ & & \\
\hline$Z 2$ & & & & & & & & & $\sqrt{ }$ & & & $\sqrt{ }$ & & \\
\hline$Z 3$ & & & & & & & & & $\sqrt{ }$ & & & $\sqrt{ }$ & & \\
\hline$S 1$ & & & & & & $\sqrt{ }$ & & & & & & & & \\
\hline$S 2$ & & & & & & & & & & & $\sqrt{ }$ & & $\sqrt{ }$ & \\
\hline$S 3$ & & & & & $\sqrt{ }$ & & & & & $\sqrt{ }$ & $\sqrt{ }$ & & $\sqrt{ }$ & \\
\hline$X 1$ & & & & & & & & & $\sqrt{ }$ & & & & $\sqrt{ }$ & \\
\hline$X 2$ & & & & & & & & & $\sqrt{ }$ & & $\sqrt{ }$ & $\sqrt{ }$ & $\sqrt{ }$ & $\sqrt{ }$ \\
\hline$X 3$ & & & & & & & & & & $\sqrt{ }$ & $\sqrt{ }$ & $\sqrt{ }$ & & $\sqrt{ }$ \\
\hline$P 1$ & & & & & & & & & & & $\sqrt{ }$ & $\sqrt{ }$ & $\sqrt{ }$ & $\sqrt{ }$ \\
\hline$P 2$ & & & & & & & & & & & & $\sqrt{ }$ & $\sqrt{ }$ & \\
\hline$P 3$ & & & & & & & & & & & & & $\sqrt{ }$ & $\sqrt{ }$ \\
\hline$P 4$ & & & & & & & & $\sqrt{ }$ & & $\sqrt{ }$ & $\sqrt{ }$ & & & \\
\hline$P 5$ & & & & & & & & & & & & $\sqrt{ }$ & $\sqrt{ }$ & \\
\hline
\end{tabular}

The ANP model of the direct risk factors of military training personnel casualty accidents and the influencing factors of human unsafe behavior is constructed by using super decisions software, as shown in Figure 4 and figure 5.

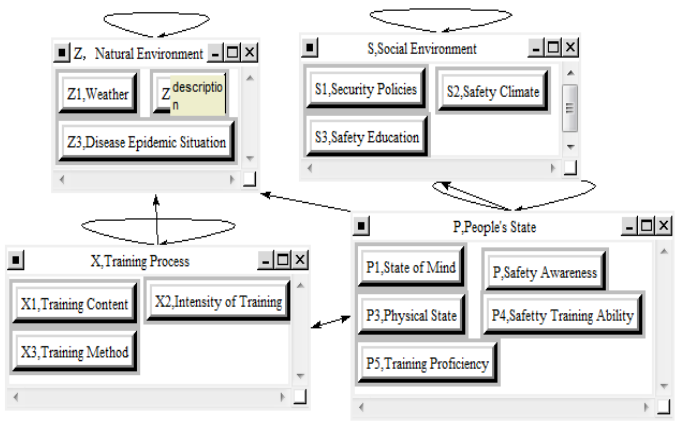

FigURE 4 ANP MODEL OF DIRECT RISK FACTORS OF CASUALTY ACCIDENT 


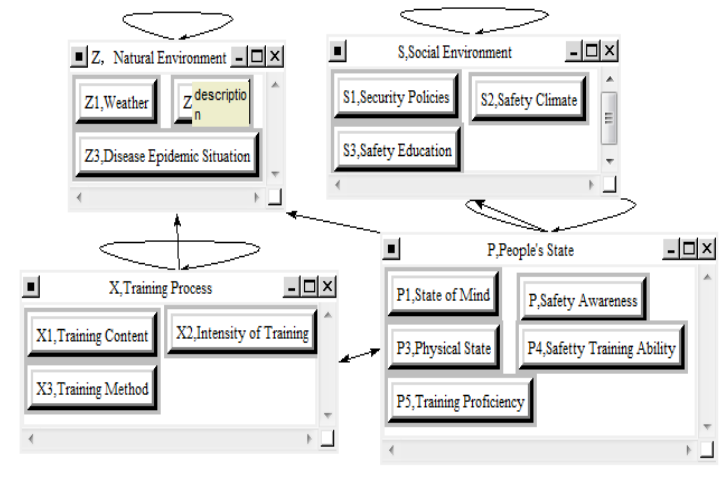

FiguRE 5 ANP Model of Influencing Factors of Unsafe Behavior of People

\subsection{Improved ANP}

The traditional ANP method uses the "1-9" scale method to compare each element group and each element in the network layer, and score their importance. It doesn't take into account the fuzziness of people's judgment, so it is difficult to give a definite value when evaluating the importance of the two factors, which leads to the obvious subjective influence on the expert scoring and affects the objective and accurate decision-making. Based on the traditional ANP method, F-ANP method introduces the thinking of fuzzy evaluation, which makes the thinking process of people's subjective judgment engineering and reduces the adverse impact of personal subjective preference on decision-making as much as possible. Literature [8] - [10] proposed the method of constructing weighted matrix based on DEMATEL, literature [6] [12] proposed the method of constructing judgment matrix by using different triangular fuzzy numbers, and literature [11] proposed the method of constructing judgment matrix by using intuitionistic voting order, which effectively improved the accuracy and reliability of ANP model calculation. This paper uses the improved triangular fuzzy number method proposed in reference [6] to judge the pairwise comparison of factors.

Suppose that there are $P$ experts in total, and the $i$ expert uses fuzzy numbers 1-9 to express his judgment, $i=(l, k, u), l, k, u$ are $\mathrm{m}$ and $\mathrm{n}$ respectively, and the minimum value, the most likely value and the maximum value of their importance are obtained by pairwise comparison, $i=1,2, \ldots, P$. The triangular fuzzy numbers obtained by pairwise comparison are integrated into one

$$
a_{m n}=\left(\begin{array}{lll}
a_{m n}, & \left.a_{m n k}, \quad a_{m n u}\right)=\left(\sum_{i=l}^{P} a_{m n i} / P, \quad \sum_{=l}^{P} a_{m n i l} / P, \quad \sum_{=l}^{P} a_{m n i l} / P\right.
\end{array}\right)(3)
$$

Constructing fuzzy evaluation factor matrix

$$
E=\left[\begin{array}{cccc}
1 & 1-\frac{u_{12}-l_{12}}{2 k_{12}} & \cdots & 1-\frac{u_{1 n}-l_{1 n}}{2 k_{1 n}} \\
1-\frac{u_{21}-l_{21}}{2 k_{21}} & 1 & \cdots & 1-\frac{u_{2 n}-l_{2 n}}{2 k_{2 n}} \\
\vdots & \vdots & \vdots & \vdots \\
1-\frac{u_{n 1}-\ln _{11}}{2 k_{n 1}} & 1-\frac{u_{n 2}-\ln _{n} 2}{2 k_{n 2}} & \cdots & 1
\end{array}\right]
$$

$\frac{u_{i j}-l_{i j}}{2 k_{i j}}$

is the standard deviation, which indicates the fuzzy degree of expert evaluation and reflects the credibility of expert evaluation.

The judgment matrix

$$
Q=M \cdot E
$$

$M$ is the median matrix, which is transformed into a diagonal judgment matrix of 1 , and then calculated according to the steps of AHP, the weight distribution of each element in the system can be obtained.

\subsection{Calculation Results}

Ten experts are invited to evaluate the direct risk factors of casualties in military training, which are not listed here due to the large amount of process data. After calculation, the weights of direct factors of safety accident risk are

\begin{tabular}{|c|c|c|}
\hline \multicolumn{3}{|c|}{ Here are the priorities. } \\
\hline Name & $\longdiv { \text { Normalized by Cluster } }$ & Limiting \\
\hline $\begin{array}{l}\text { R1,Personnel Operation or } \\
\text { Training Action }\end{array}$ & 0.43107 & 0.281525 \\
\hline R2, Training Organization & 0.56893 & 0.371563 \\
\hline $\begin{array}{l}\text { W1,Requirments of } \\
\text { Training }\end{array}$ & 0.72750 & 0.132947 \\
\hline W2, State og Human & 0.20122 & 0.036771 \\
\hline W3, State of Weapon & 0.07128 & 0.013026 \\
\hline E1, Weather & 0.68872 & 0.113065 \\
\hline E2, Terrian & 0.13784 & 0.022629 \\
\hline $\begin{array}{l}\text { E3, Disease Epidemic } \\
\text { Situation }\end{array}$ & 0.17344 & 0.028474 \\
\hline opy Values & & \\
\hline
\end{tabular}
shown in Figure 6, and the weights of influencing factors of people's unsafe behavior are shown in Figure 7.

\begin{tabular}{|c|c|c|}
\hline \multicolumn{2}{|c|}{ Here are the priorities. } & \multirow[b]{2}{*}{ Limiting } \\
\hline Name & $\longdiv { \text { Normalized by Cluster } }$ & \\
\hline P1, State of Mind & 0.11510 & 0.022061 \\
\hline P, Safety Awareness & 0.03157 & 0.006052 \\
\hline P3,Physical State & 0.02519 & 0.004828 \\
\hline $\begin{array}{l}\text { P4,Safetty Training } \\
\text { Ability }\end{array}$ & 0.72337 & 0.138652 \\
\hline P5,Training Proficiency & 0.10477 & 0.020082 \\
\hline S1, Security Policies & 0.62728 & 0.397109 \\
\hline S2, Safety Climate & 0.04769 & 0.030188 \\
\hline S3, Safety Education & 0.32503 & 0.205764 \\
\hline $\mathrm{X} 1$, Training Content & 0.45033 & 0.069932 \\
\hline $\mathrm{X} 2$, Intensity of Training & 0.31559 & 0.049008 \\
\hline X3, Training Method & 0.23409 & 0.036352 \\
\hline Z1, Weather & 0.74124 & 0.014804 \\
\hline Z2, Terrian & 0.12157 & 0.002428 \\
\hline $\begin{array}{l}\text { Z3,Disease Epidemic } \\
\text { Situation }\end{array}$ & 0.13719 & 0.002740 \\
\hline opy Values & & \\
\hline
\end{tabular}

FIGURE 6 Weight of Direct Factors of Training Safety Accidents

FigURE 7 WEIGHT OF INFLUENCING FACTORS OF UNSAFE BEHAVIORS OF PEOPLE

Among the direct factors causing safety accidents, personal action or operation, organization and implementation of training, and training standards and requirements account for 0.84 , which are the main inducing factors of training safety accidents and are consistent with the actual training. Among the unsafe behavior factors, safety system, safety education and safety training ability accounted for 0.74 , which were the main factors affecting people's unsafe behavior. 


\section{Quantitative Assessment of Safety Risk Factors}

Because it is difficult to calculate the risk factors of military training directly by data, this paper uses the method of fuzzy mathematics to determine the quantitative index of risk factors. The basic steps are as follows:

- Determine the evaluation index set $\mathrm{U}$ : the evaluation object. In this paper, refers to all kinds of security risk factors in military training;

- Determine the comment set V: In reference [1], the accident level is divided into four levels: general accident, major accident, major accident. Therefore, this paper divides the safety risk evaluation set into five levels, namely $\mathrm{V}=\{\mathrm{N}$ (negligible), G (general), M ( major), E (extra large) $\}$;

- $\quad$ Single factor fuzzy evaluation: Determine the risk level of each risk factor and get the risk level.

- Multi-factor comprehensive evaluation: all single factor evaluation results $\mathrm{F}=\left\{\mathrm{F}_{1}, \mathrm{~F}_{2}, \ldots, \mathrm{F}_{\mathrm{n}}\right\}^{\mathrm{T}}$, combined with the weight of each factor, the final evaluation conclusion is obtained, $\mathrm{F}^{\prime}=\mathrm{W} \cdot \mathrm{F}, \mathrm{W}$ is the weight.

In military training security, not only the risk factors interact with each other, but also the risk caused by each risk factor. The expert scoring will also be affected by subjective factors. For example, in the weather factors, the temperature at $32{ }^{\circ} \mathrm{C}$ is a lower risk, and the humidity at $75 \%$ is a lower risk. But the two factors combined are general risks, so we should pay attention to them The weather factors were integrated into one factor for comprehensive evaluation. In the single factor fuzzy evaluation, the expert scoring method is used to evaluate it. Combined with the actual situation of a unit's live firing training, the conversion of expert scoring is shown in Table III and table IV.

Table III. Training Safety Accident Direct Factor Expert Scoring

\begin{tabular}{|c|c|c|c|c|c|c|}
\hline \multirow{2}{*}{ Clusters } & \multirow{2}{*}{ Elements } & \multicolumn{6}{|c|}{ Severity } \\
\cline { 2 - 7 } & & $\boldsymbol{N}$ & $\boldsymbol{L}$ & $\boldsymbol{G}$ & $\boldsymbol{M}$ & $\boldsymbol{E}$ \\
\hline \multirow{3}{*}{$\boldsymbol{E}$} & $\boldsymbol{E} 1$ & 0.2 & 0.3 & 0.4 & 0.1 & 0 \\
\cline { 2 - 7 } & $\boldsymbol{E} 2$ & 0.4 & 0.4 & 0.2 & 0 & 0 \\
\cline { 2 - 7 } & $\boldsymbol{E 3}$ & 0 & 0.2 & 0.3 & 0.4 & 0.2 \\
\hline \multirow{3}{*}{$\boldsymbol{R}$} & $\boldsymbol{R} 1$ & 0 & 0.2 & 0.4 & 0.3 & 0.1 \\
\cline { 2 - 7 } & $\boldsymbol{R 2}$ & 0 & 0.5 & 0.3 & 0.2 & 0 \\
\hline \multirow{3}{*}{$\boldsymbol{W}$} & $\boldsymbol{W 1}$ & 0.4 & 0.3 & 0.3 & 0 & 0 \\
\cline { 2 - 7 } & $\boldsymbol{W 2}$ & 0.5 & 0.3 & 0.2 & 0 & 0 \\
\cline { 2 - 7 } & $\boldsymbol{W 3}$ & 0.4 & 0.3 & 0.3 & 0 & 0 \\
\hline
\end{tabular}

Table IV. Expert Score of Influencing Factors of Unsafe Behavior

\begin{tabular}{|c|c|c|c|c|c|c|}
\hline \multirow{2}{*}{ Clusters } & \multirow{2}{*}{ Elements } & \multicolumn{5}{|c|}{ Severity } \\
\hline & & $N$ & $L$ & $G$ & $M$ & $E$ \\
\hline \multirow{3}{*}{$Z$} & $Z 1$ & 0.2 & 0.3 & 0.4 & 0.1 & 0 \\
\hline & $Z 2$ & 0.4 & 0.4 & 0.2 & 0 & 0 \\
\hline & $Z 3$ & 0 & 0.2 & 0.3 & 0.4 & 0.2 \\
\hline \multirow{3}{*}{$S$} & $S 1$ & 0.7 & 0.1 & 0.2 & 0 & 0 \\
\hline & $S 2$ & 0.2 & 0.3 & 0.3 & 0.2 & 0 \\
\hline & $S 3$ & 0.1 & 0.3 & 0.4 & 0.2 & 0 \\
\hline
\end{tabular}

\begin{tabular}{|c|c|c|c|c|c|c|}
\hline \multirow{3}{*}{$\boldsymbol{X}$} & $\boldsymbol{X 1}$ & 0 & 0.2 & 0.4 & 0.3 & 0.1 \\
\cline { 2 - 7 } & $\boldsymbol{X} \mathbf{2}$ & 0.1 & 0.3 & 0.4 & 0.2 & 0 \\
\cline { 2 - 7 } & $\boldsymbol{X} \mathbf{3}$ & 0.5 & 0.3 & 0.2 & 0 & 0 \\
\hline \multirow{4}{*}{$\boldsymbol{P}$} & $\boldsymbol{P 1}$ & 0.4 & 0.3 & 0.3 & 0 & 0 \\
\cline { 2 - 7 } & $\boldsymbol{P 2}$ & 0.3 & 0.4 & 0.2 & 0.1 & 0 \\
\cline { 2 - 7 } & $\boldsymbol{P 3}$ & 0.5 & 0.4 & 0.1 & 0 & 0 \\
\cline { 2 - 7 } & $\boldsymbol{P 4}$ & 0.2 & 0.2 & 0.4 & 0.1 & 0.1 \\
\cline { 2 - 7 } & $\boldsymbol{P 5}$ & 0.4 & 0.3 & 0.2 & 0.1 & 0 \\
\hline
\end{tabular}

The comprehensive index of military training safety risk is $\mathrm{F}_{\mathrm{E}}^{\prime}=\mathrm{W}_{\mathrm{E}} \cdot \mathrm{F}_{\mathrm{E}}=$

$(0.1924,0.2962,0.3544,0.1393,0.0355) ; \mathrm{F}_{\mathrm{R}}=$

$(0,0.3671,0.3443,0.2443,0.0443)$;

$\mathrm{F}^{\prime}{ }_{\mathrm{W}}=(0.4203,0.3000,0.2798,0,0)$;

Security risk composite index of the military training

$\mathrm{F}^{\prime}=(0.0956,0.3472,0.3342,0.1895,0.0356)$.

Similarly, we can get the risk index

$\mathrm{F}_{\mathrm{z}}^{\prime}=(0.1969,0.2984,0.3620,0.1290,0.0274)$;

$\mathrm{F}_{\mathrm{S}}=(0.4812,0.1745,0.2698,0.0745,0)$;

$F^{\prime}{ }_{X}=(0.1487,0.2550,0.3532,0.1982,0.0450)$;

$F^{\prime}=(0.2547,0.2334,0.3537,0.0860,0.0723)$.

The comprehensive evaluation results of human unsafe behavior are as follows

$F^{\prime}=(0.3805,0.2008,0.3007,0.0970,0.0214)$.

According to the principle of maximum membership degree, the security risk of this military training is general risk, in which the environmental factor is the greater risk, the human behavior is the general risk, and the state risk of objects can be ignored. In the unsafe behavior of human, the risk of natural environment is greater, the risk of social environment is negligible, the risk of training process is greater, and the risk of personnel status is greater. Therefore, the focus of the safety prevention and control of the live firing training is various risks of the natural environment, scientific control of the training process and effective control of personnel.

\section{Conclusion}

The goal of security risk assessment in military training is to prevent security accidents and create good conditions for the generation of combat effectiveness. Practical and effective safety risk assessment is a problem that must be solved in our army's training under the new situation of strong military reform. This paper analyzes various factors causing casualties in military training by combining qualitative and quantitative analysis with FANP method, and determines the weight, and points out the key points of safety accident prevention more clearly, so that the accident prevention and control has a specific direction, and overcomes the problems caused by accidents The lack of pertinence in the prevention and control of military training safety accidents has a certain practical significance for the construction of training safety. However, in the process of analysis and evaluation, it is also found that the evaluation process is too cumbersome to facilitate the evaluation of daily training, especially in the single factor fuzzy evaluation, which needs further improvement.

\section{Reference}

1. CMC. (2020) Regulations on Military Safety 
Management .Beijing.

2. Bartholomew, Robert, Wessely, (2002) Simon. Protean nature of mass sociogenic illness: From possessed nuns to chemical and biological terrorism fears, Br J Psychiatry. 157(1): 300-306.

3. Fu Gui. (2014) Safety Management Behavior Control Method of Accident Prevention. Beijing: Science Press: 52-58.

4. Li Tong. (2009) Safety Risk Fuzzy Evaluation Method and Early Warning Management System Design for Large-scale Activities. China University of Geosciences (Beijing): 47-49.

5. Feng Junwen. (2006) Fuzzy Delphi Analytic Hierarchy Process and Its Application. Practice and Understanding of Mathematics.

6. Sui Minggang, Wei Yi. (2000) Discussion and Improvement of Weight Determination Method in Fuzzy AHP. Journal of Shanxi University, 3: 218-220.

7. Wang Haibin, Wu Kui, Chen Haidong. (2013) Improved ANP Effectiveness Evaluation Method Based on Grey Relational Analysis. Missile and Space Delivery Technology, 5.

8. Ou Yang Y P, Shieh H M, Tzeng G H. (2013) A VIKOR Technique Based on DEMATEL and ANP for Information Security Risk Control Assessment. Information Sciences, 232: 482-500.

9. Yang J L, Tzeng G H. (2011) An Integrated MCDM Technique Combined with DEMATEL for A Novel Cluster-weighted with ANP Method. Expert Systems with Applications, 38(3): 1417-1424.

10. Chiu W Y, Tzeng G H, Li H L. (2013) A New Hybrid MCDM Model Combining DANP with VIKOR to Improve E-store Business. Knowledge-Based Systems, 37: 48-61.

11. Sun Yonghe, Duan Wanchun, Xie Hui, Li Chunhao, Liu Wenwei. (2015) New Construction Method of ANP Weighted Matrix Based on System Intuitive Voting Sorting. Systems Engineering, 5.

12. Ba Zhenning, Wang Mingshuo, Liang Jianwen. (2020) Safety Risk Assessment of Municipal Drainage Network Operation Based on Improved F-ANP Method. Safety and Environmental Engineering, 6. 